\title{
Teaching Mathematics in Tomorrow's Society: A Case for an Oncoming Counter Paradigm
}

\author{
Yves Chevallard
}

\begin{abstract}
The historical analysis of mathematics teaching at secondary level shows the succession in time of different school paradigms. The present paper describes and tries to analyse a new didactic paradigm, still at an early age, the paradigm "of questioning the world", which relies heavily on four interrelated concepts, that of inquiry and of being "Herbartian", "procognitive", and "exoteric". It is the author's ambition to show, however succinctly, how the present crisis in mathematics education could hopefully be solved along these lines, which preclude recurring to strategies seeking only to patch up the old, still dominant paradigm "of visiting works".
\end{abstract}

Keywords Anthropological theory of the didactic - Inquiry - Mathematics • Paradigm of questioning the world $\cdot$ Research and study path

\section{The Anthropological Theory of the Didactic}

I formally began working on mathematics education when I joined the Institute for research on mathematics teaching (IREM) in Marseilles (France) more than forty years ago - in February of 1972 to be precise. I write these lines qua 2009 recipient of the Hans Freudenthal Medal, an honour of which I am immensely proud. It is thus my wish to respond to it by indulging in a quick outline of the main conclusions at which I have arrived, letting interested readers judge for themselves the cogency of such views.

First of all, I must say that this presentation will draw upon the theoretical framework which my name has come to be associated with, I mean ATD, i.e. the anthropological theory of the didactic. Just as there are economic or political facts, there are didactic facts, which I will refer to as a whole as the didactic. The didactic is

\footnotetext{
Y. Chevallard $(\square)$

Aix-Marseille University, Marseille, France

e-mail: y.chevallard@free.fr

(C) The Author(s) 2015 
a vital dimension of human societies. In a slightly simplified way, one can say that it is made up of the motley host of social situations in which some person does something - or even manifests an intention to do so-so that some person may "study" - and "learn"- - something. The something to be studied (and learnt) is known as the didactic stake in the situation. As you can see, this formulation formally refers to two persons. I will use the letter $y$ to denote the first person, and the letter $x$ to denote the second, so that we can say that $y$ does, or intends to do, something to help $x$ study (and learn) something. Of course, at times, $y$ and $x$ can be one and the same person. In such a (fundamental) case of self-directed learning, $x$ helps him/herself study the didactic stake. The "something" that $y$ does or intends to do is metaphorically called a didactic gesture and is part of the didactic as a whole.

Basically, didactics is the science studying the conditions that govern such "didactic situations", i.e. social situations which hinge on some "didactic triplet" comprising some $x$, some $y$, and some didactic stake $O$. The didactics of mathematics is concerned with those cases in which the didactic stake $O$ is regarded as pertaining to mathematics. More generally speaking, $O$ is what is called, in ATD, a "work", i.e. anything, material or immaterial, created by deliberate human action, with a view to achieving definite functions. To obtain more generality, let me substitute a set $X$ of persons for the person $x$, arriving thus at the "didactic triplet" $(X, y, O)$, which can model a typical high-school class $-X$ being the group of students, and $y$ the teacher to whom it befalls to teach the work $O$. Naturally, we can also consider triplets of the form $(X, Y, O)$, where $Y$ is a team of didactic "helpers" that may include a full-fledged teacher alongside "assistants" of different kinds. Let me add here that, in ATD, a condition is said to be a constraint for a person or an institution if it cannot be modified by this person or institution, at least in the short run. Now the basic question in didactics is somewhat the following: given a set of constraints $K$ imposed upon a didactic triplet $(x, y, O)$, what conditions can $x$ and $y$ create or modify-i.e. what didactic gestures can they make - in order for $x$ to achieve some determined relation to $O$ ? This will be the starting point for what follows.

\section{The Paradigm of Visiting Works and Its Shortcomings}

The prospective view on the didactic dimension in our societies that I wish to make explicit - and, I hope, clear - can be encapsulated in a crucial historical fact: the old didactic paradigm still flourishing in so many scholastic institutions is bound to give way to a new paradigm still taking its first steps. To cut a longer story short, I define a didactic paradigm as a set of rules prescribing, however implicitly, what is to be studied - what the didactic stakes $O$ can be — and what the forms of studying them are.

The "old" paradigm I've just mentioned has been preceded by a number of distinct, sometimes long-forgotten paradigms. The most archaic of these didactic paradigms disappeared, in many countries, during the nineteenth century. In the field of mathematics as well as in many other fields of knowledge, it was organised around the study of doctrines or systems - of mathematics, of philosophy, 
etc. - approached from outside and considered as outstanding achievements in the history of human creation. Within this paradigm, one used to study Euclid's Elements in the way most of us may still study (or aspire to study) Plato's or Hegel's systems of philosophy. This initial paradigm — which I call the paradigm of "hailing and studying authorities and masterpieces"- - has gradually given way to the school paradigm that nowadays all of us, willingly or not, are supposed to revel in, which evolved in the course of centuries from the older paradigm of studying "grand systems". The "great men" supposed to have authored those systems were waved aside and the systems crushed into smaller pieces of knowledge of which the authorised labels - Pythagoras, Thales, Euclid, Gauss, etc., as far as mathematics is concerned-still record their origins.

In the framework of the anthropological theory of the didactic, this paradigm is known as the paradigm of "visiting works" or-according to a metaphor used in ATD - "of visiting monuments", for each of those pieces of knowledge-e.g., Heron's formula for the area of a triangle - is approached as a monument that stands on its own, that students are expected to admire and enjoy, even when they know next to nothing about its raisons d'être, now or in the past.

In spite of the long-standing devotion of so many teachers and educators to this unending intellectual pilgrimage, notwithstanding the often admirable docility of so many students in accepting the teacher as a guide, this once pervasive paradigm is currently on the wane. This has come to be so, it can be argued, because the paradigm of visiting monuments tends both to make little sense of the works thus visited-“Why does this one happen to be here?", "What is its utility?" remain generally unanswered questions. The interested reader may want to check how this applies to a number of mathematical entities. For example, what purpose does the notion of reflex angle serve? The same question can be raised about angles in general, and also about parallel lines, intersecting lines, rays, line segments, and so on. Of course, the same goes for the reduction of fractions or polynomial expansion, with the notion of decimal number, and what have you. In what situations can this mathematical entity prove useful, if not utterly unavoidable, and how? Because these questions are usually hushed up_visiting a monument is no place to raise "What for?" or "So what?" questions_-, students are reduced to almost mere spectators, even when educators passionately urge them to "enjoy" the pure spectacle of mathematical works.

A number of factors explain at least partially the long dominance of the paradigm of visiting works as monuments as well as its present decline-and, I suggest, its impending demise. Historically, the first cause seems to be the congruity of this paradigm with the social structure of formerly undemocratic countries or, since more recent times, weakly or incompletely democratic. Such societies are founded on an all-pervasive pattern inseparably linking those in command positions, on the one hand, and those in obedience positions, on the other hand. Almost all institutions (be they families, schools, or nations) hinge on some replica of this fundamental, dualistic pattern. I shall not go into debate, here, about this age-old social structuring. I only want to emphasise the specific risks that the functioning of this ubiquitous power structure easily generates, in the form of abuses of authority, 
power, or rank - call them as you like. The existence of a dualistic configuration with one in authority and one in obedience may for sure be vindicated, on a "technical" basis, as needed to keep institutions going. But such a technically justified twofold structure is normally limited in time and, above all, in scope. Authority is, or should be, restricted to a specified number of specific situations, and should therefore refrain from encroaching on every aspect of life-unless it changes into tyranny. But respecting this rule is not everyone's forte. The classical paradigm of visiting "monuments of knowledge," however small, suffers today, at many levels, from the constant abuses of pedagogic power that its historical kinship with the dualistic pattern of power mechanically generates.

The consequences of this historical situation are many. First and foremost, I shall mention a consequence already alluded to: the resistless evolution of the school mathematics curriculum towards a form of epistemological "monumentalism" in which knowledge comes in chunks and bits sanctified by tradition and whose supposed "beauty" has been enhanced by the patina of age; that students have to visit, bow to, enjoy, have fun with and even "love". All this of course is but a daydream, as far as the mass of students-not the happy few, who need very little attention-is concerned.

The main effect of this long-term situation is the growing tendency among students to develop a relation to "official", scholastic knowledge in agreement with what I shall term the "Recycle bin/Empty recycle bin" principle: all the knowledge taught may legitimately be forgotten or, more exactly, ignored, as soon as exams have been passed. Of course this is presumably as old as the school-and-exam system. But it has shaped a relation to knowledge as driven by institutional, shortterm, and labile motives, which stands away from the functional approach to knowledge based on its real-world utility - to understand a situation, be it mathematical or not, make a decision, or postpone it to allow for further study of the problem addressed.

A correlate, if not properly a consequence, is to be found in a yet more challenging fact: what little knowledge remains after the school years is rarely regarded as something that could bear on situations one might face outside school—and this seems particularly true in the case of mathematical knowledge. School-generated knowledge tends therefore to be unusable, in that its "remnants" are unable to perform their specific function. But there is more to it than that. Visiting a monument basically boils down to listening to a report or account made by the teacher-guide about the monument visited-what we call in the French of ATD an exposé, a word from whose meaning the negative connotation it has acquired in English must be expelled in this context. By its very nature, any account, a report, or an exposé skips "details", i.e. aspects that, more or less arbitrarily, choice-makers have ignored or altogether discarded. To give just one example, in the French curriculum-as is the case, I presume, in many other mathematics curricula across the world-, tradition has it that the algebraic solving of cubic equations is overlooked, while quadratic equations are emphatically considered. In his/her scholastic visit of the mathematical universe, the student thus reaches an endpoint beyond which lie mathematical _territories that, more often than not, will remain indefinitely terra incognita to 
him/her. What will be of this student if, in later life, they need to know what a cubic equation is and how it can possibly be solved? School education along the lines of the current paradigm has no clear answer to that question, it seems.

The relation to knowledge and ignorance thus associated with the visiting of mathematical works has become increasingly unsuited to people's needs and wants, up to the point that there currently exists a widespread belief that mathematical knowledge is something one can almost altogether dispense with-whereas, in a not so remote past, mathematics could be regarded as the key to a vast number of individual as well as collective problems. In this respect, the chief flaw in the paradigm of visiting monuments, which relates to the undemocratic ethos in which this paradigm originated, has to do with the choice of "monuments" to visit at school. As we know, this choice is usually the combined result of a long-lasting tradition, on the one hand, and of irregularly spaced, hectic reforms, on the other. In no way, it seems, the decisions made go beyond what the people in charge of this choice-making think opportune, fit, or even "good" for the edification of the mounting generations. In no way, it seems, is the choice of the monuments to be visited made on an experimental basis or at least on a large and supposedly relevant experiential basis. In what follow, I will try to adduce evidence that such a "feat" can be achieved provided we opt for the emerging didactic paradigm I call the "paradigm of questioning the world".

\section{Questioning the World: Towards a New Didactic Paradigm}

Up to a point, we might soon discard the current didactic world in favour of a new paradigm which, when contrasted with the old one, looks like a counterparadigmalthough, as we shall see, it isn't doomed to break off all contact with its predecessor. The main changes that I shall stress are few but radical. Let us consider again a triplet $(X, Y, O)$. An almost inconspicuous but crucial tenet of traditional education is that the members $x$ of $X$ are children or adolescents: traditionally, the educational endeavour is about young people, before they attain maturity. When maturity has been reached, everyone is supposed to be educated-well or badly, that is another question. In contrast with this view of education, in the didactic paradigm of questioning the world, education is a lifelong process. The $x$ in the triplet $(x, y, O)$ can be a toddler as well as a mature adult or an older person. A society's didactic endeavour is regarded (and assessed) as applying to all— to citizens no less than to future citizens. Consequently, the assessment of this crucial endeavour can no longer focus on young people only: not only should we explore what 15-year olds happen to know, but we should extend this quest to people aged 30 to (at least) 70. More than anything, society's didactic effort is not simply known by what people know: it should be appraised on the basis of what they can learn - and how they can do so.

A second, central tenet of the paradigm of questioning the world is that, in order to learn something about some work $O, x$ has to study $O$, often with the help of some $y$. You don't learn to solve a cubic equation by chance; you have to stop and 
consider the question that arises before you. In today's common culture, many people, it seems, have a propensity to shun every question to which the answer is not obvious to them. What the new didactic paradigm aims to create is a new cognitive ethos in which, when any question $Q$ arises, $x$ will consider it, and, as often as possible, will study it in order to arrive at a valuable answer $A$, in many cases with a little help from some $y$. In other words, $x$ is supposed not to systematically balk at situations involving problems that he/she never came across or never solved. For reasons I shall not comment on, I call Herbartian-after the German philosopher and founder of pedagogy Johann Heinrich Herbart (1776-1841) - this receptive attitude towards yet unanswered questions and unsolved problems, which is normally the scientist's attitude in his field of research and should become the citizen's in every domain of activity.

The new didactic paradigm wants the future as well as the full-blown citizen to become Herbartian. Let me give three easy, miscellaneous examples of possibly impending "open" questions. First example: many people engaged in social science research but who have had little contact with statistics during their school or college years may come across Pearson chi-squared test, bump into the elusive notion of degrees of freedom, and become obsessed with the question "What does the expression 'degrees of freedom' mean exactly?" Second example: physics students may be upset about having to use the curious symbol "proportional to" $(\alpha)$, "an eight lying on its side with a piece removed" (Miller 2011), without having the slightest idea about how the manipulation of this symbol can be justified in mathematical terms, particularly as concerns the intriguing conclusion that, if a variable $z$ is proportional to variables $x$ and $y$, then $z$ will also be proportional to their product $x y$. Third example: anyone interested in the question of biodiversity may stumble upon a mathematical equation such as this:

$$
H_{e}=1-\frac{1}{1+4 N_{e} \mu}
$$

For the unrepentant non-mathematician, the first question will be: "What does that mean? What does that entail?" For all of us, I suppose, a second question will soon emerge: "Where does it come from? How can it be arrived at?" Of course, the pre-Herbartian citizen generally ignores all these questions because he/she usually recoils from anything seemingly mathematical. But the citizen in tune with the new didactic paradigm will face the questions, and, whenever possible, will come to grips with each of them. How is that possible?

In the didactic world shaped by the paradigm of visiting monuments, most people behave "retrocognitively". I use the word "retrocognition" not in its old parapsychological sense but simply to express the cognitive attitude that leads one to refer preferentially and almost exclusively to knowledge already known to one. Retrocognition in this sense is governed by the quasi-postulate according to which, once your school and college years are over, if you don't know in advance the answer to the question that faces you, then you'd better renounce all pretension to arrive at a sensible answer. This, of course, correlates with the propensity I mentioned earlier for 
staying away from unheard-of questions. By contrast, the paradigm of questioning the world calls for a very different attitude, that I dub procognitive (in a sense unrelated to the use of the word in denoting a drug that "reduces delirium or disorientation"), and which inclines one to behave as if knowledge was essentially still to discover and still to conquer-or to rediscover and conquer anew. In the retrocognitive bent, therefore, knowing is "knowing backwards"; whereas in the procognitive dedication, knowing is "knowing forwards".

In the scenario I present, how does one construct and validate an answer $A$ to a question $Q$ ? Basically, inquiring into a question $Q$ requires a twofold move. In the first place, the "inquirer" $x$ will search the relevant literature for existing answers to question $Q$ - a move traditionally banned at school, while to the contrary it is unavoidable in scientific research. In ATD it is common to denote an existing answer by the letter $A$ with a small lozenge or diamond - a "thin" rhombus - in superscript, $A$ ", in order to express that such an answer has been created and diffused by some institution which, in some sense, hallmarked it. Of course an answer $A$ " needs not be "true" or "valid"; but it is up to $x$ to evaluate answers $A^{\diamond}$ to see if they are relevant—which also departs from school usage, in which answers provided by the teacher are guaranteed by the same token. In order to arrive at a proper answer-usually denoted by the letter $A$ with a small heart in superscript regarded as the "maker's mark": $A$ - the inquirer $x$ has to use "tools", mathematical or not, i.e. works of different nature. It is from the combined study of the "hallmarked" answers $A^{\diamond}$ and of the works $O$ (used as tools both to study answers $A^{\diamond}$ and to construct an answer $A^{\bullet}$ ) that the process of research for an answer $A^{\bullet}$ will get under way.

The inquiry led by $x$ into $Q$ opens up a path called a research and study path (or trail, or track, or course, etc.). To proceed along this path, the inquiry team $X$ has to use knowledge - relating to answers $A^{\diamond}$ as well as to the other works $O$ - hitherto unknown to its members, that the team will have to get familiar with to be able to continue on the trail towards answer $A^{\bullet}$. A necessary condition in this respect is for $X$ and for every member $x$ of $X$ to behave procognitively, looking forward to meeting new knowledge - new works - without further ado.

Some more didactic aspects should be stressed here. Firstly, in the paradigm of questioning the world, encountering new knowledge or e-encountering old, halfforgotten knowledge along the research and study path is the way that inquirers $x$ learn - they learn or relearn the answers $A^{\diamond}$, the working tools $O$ and, finally, the answer $A^{\bullet}$. It should then be clear that the contents learnt, in this context, have not been planned in advance-contrary to what is usual in the paradigm of visiting monuments - and are determined essentially by two factors: by the question $Q$ being studied, in the first place, and then by the research and study path covered, which in turn is determined by the $A^{\diamond}$ and the $O$ encountered and studied in order to build up the answer $A^{\bullet}$. Secondly, it must be emphasised that studying a (mathematical or non-mathematical) work $O$ - the same holds for the answers $A^{\diamond}$-is determined by the project of arriving at an answer $A^{\bullet}$. Contrary to the fiction forced upon $x$ and $y$ in the paradigm of visiting works, there is no such thing as a "normal" or "natural" study of a given work $O$. All exposés are special, none is exhaustive, and most fail to conceal their arbitrariness. The study of a work $O$ in the context of 
an inquiry into some question $Q$ will heavily depend, both quantitatively and qualitatively, on the use of $O$ in the making of the answer $A$. What should be clear in such a context-bound study of $O$ is that the knowledge of $O$ thus acquired by the investigators is functionally coherent because it is cohered by the inquiry into question $Q$, so that the raisons d'être of $O$ that do explain its use in the case in point are readily apparent.

\section{Society, School, and the New Paradigm}

The paradigm of questioning the world and the inquiries that make it a reality do not exist in a vacuum. They must have a basis in society and in school. Once again let me stress here that the field of relevance of the didactic schema-called the Herbartian schema - outlined so far extends to the whole of society-it is not conceived as being restricted to school. Any person can represent $x$ in a didactic triplet $(x, y, O)$. [A didactic "helper" $y$ may fail to exist, in which case it is common to write the triplet in the form $(x, \varnothing, O)$ : the didactic triplet is then reduced in actual fact to a 2-tuple.] Of course it is easy to spot an outstanding difference. In many modern societies, going to school during the first part of one's life-while you're a youngster - is compulsory. Admittedly, there is no such thing as compulsory education for adults in general. In this respect, the scenario advocated here supposes a fundamental change, with the extension of the right to education into the right to lifelong education for all, provided by an adequate infrastructure that we could continue to call "school", but in a sense that goes back to ancient Greece and, more precisely, to the Greek word skhole, which originally designated spare time devoted to leisure (this was still its meaning in the time of Plato, for example), but which evolved to mean "studious leisure", "place for intellectual argument", and "time for liberal studies". The new role of the didactic in our societies thus implies the development of a ubiquitous institution that, in what follows, I shall term, more genuinely, skhole. Of course, school as we know it is a key component of skhole, even though, in its present form, it remains largely foreign to the new didactic paradigm. But school is not all of skhole. For example, for adults as well as for younger people, a good part of skhole takes place at home: home skholeing will be, and already is, a master component of skhole. In what follows, skhole will be approached for its capacity to favour the development and flourishing of the paradigm of questioning the world - even though parts of it are still under the control of the old school paradigm.

I begin by considering the case of adults' skholeing — of which today's "adults schooling", as we may call it, is but a meagre component. In truth, many citizens are already, though partially, equipped to inquire on their own into the many questions that may beset them, for example in their daily life. This being noted, what are the main constraints that hinder, and what are the conditions that might favour the development of adults' skholeing? The first condition lies in the fact that, instead of fleeing when faced with questions, $x$ duly confronts them. To do so, $x$ has 
to formulate them explicitly, at least for him/herself. Simple as it may sound, such a move conflicts with a fundamental determinant of our cultures, the disjunction between "masters" and "underlings", if I may say so, that forbids the latter to raise questions about the world — natural or social—, or, as the saying goes, to put it "into question", while "masters" have alone the legitimacy to question the world and to change it. Sheer observation-but this conclusion can easily be submitted to experimentation - shows that most people get excited at daring to pose on their own the merest question. Historically, posing questions was the privilege of the mighty, although it has become a defining right of citizens; but it is a right not yet exercised as it should in a fully developed democracy.

Let us suppose that some citizen has decided to inquire into some question $Q$, becoming thus an inquirer $x$ in a triplet $(x, ?, Q)$. At this stage of his/her study, two problems face him/her. On the one hand, $x$ may think of getting help from some people $Y$; on the other hand, he/she will have to "search the world" for answers $A$ " to question $Q$ and relevant works $O$. The first of these two problems has no systematic solution today. The second problem has a good approximate solution. It consists in the sum total of the information provided by the Internet and especially the Web. In fact, I shall refer to the Internet sensu latissimo - in the broadest sense-, a sense that, against current usage, includes... all the libraries in the world, because any document is either available on the Internet or can be regarded as not yet available on the Internet. To take here just one example, in the case of an inquiry into the mathematics of the "proportional to" symbol $(\alpha)$, when starting from Jeff Miller's well-known website on the Earliest uses of symbols of relation (2011), one is led to Florian Cajori's classic book on the history of mathematical notations (1993, vol. 1, p. 297), which in turn refers the inquirer to three older books, authored respectively by Emerson (1768), who was the introducer of the symbol $\propto$, Chrystal (1866), and Castle (1905). Today, all of these books are available online for free. Let us also observe that the Internet allows most inquirers $x$ to find help from occasional helpers $y$, for example on Internet forums and discussion threads, so that the main solution to the second problem also supplies a (partial) solution to the first problem.

Making inquiries on the Internet sensu latissimo meets with well-recognised difficulties. First, if $x$ is almost certain to come across at least some relevant resources, documents allowing him/her to go further and deeper into the question studied may be scarce. Second, the inquirer $x$ can prove unable both to find out relevant documents that do exist and to make the most of what little information he/she culled. The inquirer's intellectual equipment-or more exactly the inquirer's praxeological equipment, in a sense of the word praxeology proper to ATD - thus rests on two pillars: the capacity to locate resources, online and offline, and the knowledge necessary to take advantage of them. This leads to the question of making good use of the works $O$ gathered. Most general questions $Q$ entail the use of works $O$ pertaining to different branches of knowledge, so that the study of $Q$ is bound to be a co-disciplinary pursuit, bringing together for a common endeavour tools from different "disciplines". It should be stressed at this point that what I've called a citizen is not a person reduced to being a member of a political community. But, much to the contrary, he/she is considered according to his/her accomplishments and potential, particularly as an 
inquirer into questions of any breed. It results from this that a citizen does not only have to be educated in many fields but, in the procognitive perspective of the new didactic paradigm, a citizen must be ready to study and learn, even from scratch, fields of knowledge new to him/her. A citizen is not only a law-abiding person; he/she also has to become a knowledgeable person, indefinitely ready to study works hitherto unknown to him/her, just because some inquiry calls for their study.

The citizen I portray here may feel unable to live up to what is thus required of him/her. This feeling essentially results from the old didactic organisation of school and society that has imposed upon us the illusion according to which, for any knowledge need we may experience, there somewhere exists a providential person who can teach us whatever we want to know. Such a puerile belief leads to passivity and submission to events outside our reach. In the paradigm of questioning the world, attending a course or a conference on some subject of interest is certainly not disregarded. But we should take them as means to a common end-learning something on some determined work $O$ supposed to be useful in order to bring forth an answer $A^{\boldsymbol{\bullet}}$ to question $Q$. In such a situation, because of a relation to ignorance and knowledge resulting from exposure to the old school paradigm, we are prone to feel frustrated at not having all the knowledge needed-all of history, biology, mathematics, physics, chemistry, philosophy, linguistics, sociology, and so on indefinitely. The character implicitly fantasised here is what I've come to call an esoteric (using thus the adjective also as a noun), who is supposed to already know all the knowledge needed (the idea most people have of "a historian", "a biologist", "a mathematician", "a physicist", etc., is commonly akin to this fantasy). By contrast, an exoteric has to study and learn indefinitely, and will never reach the elusive status of esoteric. Indeed, all true scholars are exoteric and should remain so in order to remain scholars: esotericism, as I define it here, is a fable.

The citizen in the new paradigm is therefore called upon to become Herbartian, procognitive, and exoteric. How can we promote this new citizenship? Beyond being possessed by the epistemological passion necessary to go all the way from pure ignorance to adequate knowledge, a crucial condition is, for sure, the time allotted to study and research in an adult's life. More often than not, it seems, this time tends to zero as years pass by. In this respect, I suggest that we repeat again and again the founding trick of the ancient Greeks - that of transmuting leisure time, which some of our contemporaries seem to enjoy so abundantly, into study and research time, in the authentic tradition of skhole. Such a pursuit pertains to what Freud once called Kulturarbeit, "civilisational work" - a radical change still to come, which is a sine qua non of the emergence of the new didactic paradigm.

The problem of the time allotted to study and research has an easy solution when it comes to ordinary schooling: youngsters go to school to study, in accordance with skhole's defining principle. But in what measure does school welcome the new didactic paradigm? I shall not dwell too long on this subject. I will, however, suggest that in too many cases, the so-called "inquiry-based" teaching resorts to some form or another of "fake inquiries", most often because the generating question $Q$ of such an inquiry is but a naive trick to get students to find and study works $O$ that the teacher will have determined in advance. Of course, this is the 
plain consequence of the domination of the paradigm of visiting works, which implies that curriculum contents are defined in terms of works $O$. In contradistinction, in the paradigm of questioning the world, the curriculum is defined in terms of questions $Q$. However, the works $O$ studied in consequence of inquiring into these questions $Q$ play a central role in the process of defining and refining the curriculum: starting from a set $Q$ of "primary" questions, the curriculum contents $C$ eventually studied will include the questions $Q$ and answers $A^{\bullet}$, together with the answers $A^{\diamond}$ and the works $O$.

At this point two questions arise, though. The first question relates to the set $Q$ of "primary" questions: where do these questions come from, and according to what mechanisms? In the case of a national curriculum, the set of primary questions to be studied at school constitutes the "core curriculum", and therefore the foundation of the national pact between society and school. Consequently, it is up to the nation to watchfully and democratically decide what the set $Q$ will consist of and to periodically revise and update its contents on the basis of a careful monitoring of the curriculum's life-cycle. Because it is essential to the relationship between a society and its schooling system, the core curriculum - i.e. the "primary" questions - will play a decisive part in the society's skhole. But it should be obvious that the curriculum is not precisely defined by the primary questions alone. The inquiries entailed by these questions are in no way uniquely defined: as we know, an inquiry may follow different paths of study and research, and the questions inquired into as well as the other works encountered and, up to a point, studied, are indeed pathdependent. As a result, even if the core curriculum (in the sense defined above) has been made precise, the ensuing curriculum might well look fuzzily defined because of its built-in variability. How can this situation be managed for the better?

Let us consider didactic triplets $(X, Y, O)$ with $O$ a (finite!) family of questions. We can envisage two types of didactic triplets associated with a class of students. First, there is a seminar, in which $O$ is a dynamic family of questions comprising the primary questions and the questions their study will generate. (Remember that the scenario delineated is supposed to apply to advanced students as well as to... toddlers, so that the words I use here must be taken in a very broad sense, which allows for their adaptation to a wide variety of concrete conditions.) This seminar will essentially be co-disciplinary, for primary questions rarely fall into a unique disciplinary domain. Second, there will be disciplinary workshops to study the questions and works put forward in the seminar but which pertain essentially to a given discipline - there will be for example a chemistry workshop, a mathematics workshop, a history workshop, a biology workshop, and so on. The activated workshops may vary depending on the primary questions studied in the seminar. The key fact is that, in this two-step process (seminar plus workshops), some works $O$ and disciplines will be insistently recurrent, because they will be more often called upon in the inquiries, while others will be encountered erratically or will almost never turn up. This "degree of mobilization" of a work $O$, if averaged nationally across all the seminars held at a given school level, gives the "degree of membership" of the work $O$ to the curriculum regarded, metaphorically, as a continually redefined fuzzy set - a view more adequate to the true nature of a real 
curriculum. As indicated above, and contrary to the age-old habit of imposing a curriculum founded essentially on opinion, the paradigm of questioning the world makes it possible to bring to light in an organic way which resources are really used in trying to question and know the world, both natural and social.

\section{What Will Be the Place of Mathematics?}

At a given point in time, an inquiry may come to a stop because some useful tool proves unavailable to the inquirers. One major reason for which an inquiry may thus grind to a halt is that the mastery of essential parts of some work $O$, ideally required to continue progress, lie well beyond the inquirers' reach. This, it should be stressed, is the common law of inquiry, be it at school or in a research team, and is definitely not the preserve of "low-level exoterics": it is part and parcel of the art of inquiry-such an "incident" is but one of the twists and turns in an inquirer's venture. But the path followed in a given inquiry, whatever its determinants, has crucial consequences in the didactic scenario displayed above: if a work $O$ is very rarely drawn upon in seminars and workshops across the nation, then this work $O$ will eventually vanish from the national curriculum. To be quite frank, this can result in the disappearing of parts of traditional school disciplines; for the place occupied by a discipline in the new curriculum will depend on its effectiveness in providing tools for inquiring into the curriculum-generated questions; it will depend no longer on any formerly or recently established hierarchy of disciplines, held to be the unquestionable legacy of the past. Traditionally flourishing disciplines should then worry about their future at school: will they continue to thrive or will they soon languish? The question is put to every discipline, and especially to mathematics.

If knowledge is valued according to what it enables us to rationally understand and achieve, the problem we are confronted with is not so much the fate of the disciplines as the value and quality of the inquiries going on in the seminars and workshops. From this point of view, the foregoing scenario can be improved substantially by allowing for the possibility to append "control questions" to any question pertaining to the curriculum. In some sense, this adds, to the bottom-up information flow emanating nationwide from the seminars and workshops, a topdown regulatory control on schools, operated by supervisory authorities. Any question $Q$ can indeed be supplemented meaningfully by one or a series of "side questions" $Q^{*}$ that will be touchstones for controlling the quality, thoroughness and profundity of an inquiry into question $Q$. It is in this way that it becomes possible to point out meaningfully - and not out of sheer pretentiousness - the utility of such and such work $O$ to get deeper into the question studied. For example, to a question about biodiversity, one might relevantly add a question about genetic diversity and, in turn, a question about the meaning and interest of Eq. (1) above, a question likely to draw the inquirers' attention to the importance of... mathematics in inquiring into genetic diversity. 
For mathematics as well as for a myriad of works pertaining to the most varied fields of knowledge, such a system of control questions seems indispensable to remind the $x$ and the $y$ that inquiring into some question may require the use of tools that will first appear, from within the cultural limits that they are precisely expected to transcend, as far removed from the matter under study. This is particularly true in the case of mathematical works. For deep-rooted historical reasons, mathematics is today both formally revered and, at the same time, energetically shunned. Numerous people flee away from mathematics as soon as they are no longer obliged to "do" mathematics. This has determined many mathematics educators to engage in a strategy of seduction, with a view to regaining the favour of "mathematical non-believers" by convincing them that, as the saying goes, "maths is fun"! Let me say tersely that this strategy has two main demerits and that, in my view, it should be as such utterly discarded. The first defect seems to be liberally ignored in today's educational world: for deep political and moral reasons, the instruction imparted at school must refrain from manipulating feelings and beliefs-we must be unimpeachable as far as the liberty of conscience of $x$ (and $y$ ) is concerned. Consequently, mathematics educators must resist the temptation to try to induce students to "love" mathematics: their unique mission is to let them know mathematics, which is a bit more demanding! Love and hate are personal, intimate feelings that belong to the private sphere proper. Of course, it is highly probable that knowing mathematics better will result in some form of keenness towards mathematics. But all this entirely pertains to every single person's conscience.

The second defect of the much acclaimed seduction strategy is its very low yield, if I may say so. The problem with mathematics - as with other disciplines - is a mass problem. The root of it lies, in my view, in the process of cultural rejection that mathematics has suffered for a long time now, with the crucial consequence that, outside mathematical institutions proper, mathematics vanishes from the "lay" scene, so much so that many documents about topics not substantially foreign to mathematics can show no trace at all of mathematics, a fact which jeopardises the quality of many inquiries. Let me give here a simple example. Consider the question "Why does ice float in water?" Part of the answer is: because ice is less dense than liquid water. Now why is ice less dense than liquid water? The usual answer is that the arrangement of $\mathrm{H}_{2} \mathrm{O}$ molecules occupies more space in ice than in liquid water. A closer look at this answer leads to some easy calculations (Ravera 2012). Indeed, it can be shown that, under certain conditions, the unit cell of ice has a height of $737 \mathrm{pm}$ (i.e. $737 \times 10^{-12} \mathrm{~m}$ ), with its base a rhombus with sides of length $452 \mathrm{pm}$ and an angle of $60^{\circ}$. The volume of the unit cell is therefore

$$
V=\frac{\sqrt{3}}{2} \times 452^{2} \times 737 \times 10^{-33} \mathrm{~L}
$$

The molar mass of water is approximately $18 \mathrm{~g} / \mathrm{mol}$. The mass of a unit cell of ice is known to be that of four molecules of water. Avogadro's number is taken here to be $6.02 \times 10^{23} \mathrm{~mol}^{-1}$. Hence the mass $M$ of a unit cell: 


$$
M=\frac{4 \times 18}{6.02 \times 10^{23}} \mathrm{~g}
$$

The density of ice is therefore:

$$
d=\frac{M}{V} \approx 917 \mathrm{~g} / \mathrm{L}
$$

This (approximate) result confirms that ice is lighter than liquid water. The calculation uses elementary tools that are all (supposedly) mastered at age 15. In spite of this, this calculation is generally withheld from most relevant presentations available on the Internet. This is no exception to the rule. In a majority of cases, the mathematics of the topic being presented is decidedly absent, as if it had never existed. This is typically what mathematics educators must combat. In this respect, as far as mathematics is concerned, the "touchstone questions" that should be appended tentatively to any question proposed for study come down to this: "What are the mathematics of the matter, and how can awareness of them enhance the quality of your answer?"

Is this really a way out of the historic trap in which mathematics has been lured? I believe so. The seduction strategy, which is successful with an insignificant number of people, is but another pitfall. In my view, the only realistic solution will consist in trying to rationally persuade the citizens and, to begin with, the students that dispensing with mathematics may crucially impoverish our understanding and drastically reduce the quality of our involvement in both the natural and the social world. This, of course, will not be achieved through fine words only. It needs daily action, in schools as well as outside schools, especially in the leisure time given to learning by the citizenry to enrich their lives. In this pursuit, mathematics educators will play a crucial, though different, part.

For centuries, mathematics as a cultural institution thrived on a twofold selfpresentation: it was understood as being composed, on the one hand, of "pure" mathematics, and, on the other hand, of "mixed" mathematics, with its pervasive ethos and slightly imperialistic touch. The "mixed" part, later called "applied" mathematics, has steadily declined at school during the last decades, while what remained of the former part-pure, though elementary, mathematics - tried to symbolise and maintain the old "empire". It is my belief that this time has now come to an end. Today, we have to revive the epistemological spirit of mixed mathematics, although without any cultural arrogance, but with the political and social will necessary to revitalise the idea that mathematics is for us, human beings, a solution, not a problem.

Open Access This chapter is distributed under the terms of the Creative Commons Attribution Noncommercial License, which permits any noncommercial use, distribution, and reproduction in any medium, provided the original author(s) and source are credited. 


\section{References}

Cajori, F. (1993). A history of mathematical notations (Vols. 1-2). Mineola, N.Y.: Dover.

Castle, F. (1905). Practical mathematics for beginners. New York: Macmillan.

Chrystal, G. (1866). Algebra: An elementary text-book for the higher classes of secondary schools and for colleges (vol. 1). London: Adam and Charles Black.

Emerson, W. (1768). The Doctrine of fluxions. London: Richardson.

Miller, J. (2011, November 11). Earliest uses of symbols of relation. Retrieved from http://jeff560.tripod.com/relation.html

Ravera, K. (2012). Pourquoi la glace flotte sur l'eau. In Tangente (Eds.), Mathématiques et chimie. Des liaisons insoupçonnées (pp. 80-82). Paris: Pole. 